\title{
PENGEMBANGAN PERANGKAT PEMBELAJARAN CIRC (COOPERATIVE INTEGRATED READING AND COMPOSITION) DALAM MENINGKATKAN PEMAHAMAN MATEMATIS PADA MATERI PERBANDINGAN SISWA SMP
}

\author{
Edi Mulyadin ${ }^{1}$, Sowanto*¹, dan Dusalan ${ }^{1}$ \\ ${ }^{1}$ Sekolah Tinggi Keguruan dan Ilmu Pendidikan (STKIP) Bima \\ *Email korespondensi: sowantos@gmail.com
}

\begin{abstract}
ABSTRAK
Penelitian ini bertujuan untuk: (1) menghasilkan perangkat pembelajaran dengan model pembelajaran CIRC guna meningkatkan pemahaman siswa yang layak digunakan dalam proses pembelajaran, dan (2) mengetahui kualitas dan respon siswa terhadap perangkat pembelajaran yang telah dikembangkan dan digunakan dalam proses pembelajaran. Penelitian ini merupakan penelitian pengembangan (Research and Development) dengan model Ploomp. Subjek uji coba lapangan meliputi 30 siswa kelas VIII-7 di SMP Negeri 1 Kota Bima. Instrument yang digunakan berupa lembar validasi untuk validator (3 orang guru matematika di SMP Negeri 1 Kota Bima), lembar angket respon siswa, serta lembar observasi berupa angket soal analisis bagi siswa. Data kualitas produk yang diperoleh dari validator dianalisis dengan menggunakan analisis deskriptif, yaitu mengolah skor rata-rata aspek kualitas yang diperoleh dari nilai kuantitatif menjadi nilai kualitatif menggunakan kriteria kategori penilaian ideal. Hasil penilaian terhadap produk berupa draf RPP, LKS dan Model Pembelajaran Siswa menggunakan analisis data berupa pengolahan secara kuantitatif dan kualitatif. Penilaian dilakukan dengan mencari nilai rata-rata dari semua aspek penilaian prototipe oleh validator adalah 4,8 dengan kriteria kualitatif sangat valid. Sedangkan penilaian dari 30 siswa memiliki rata-rata nilai sebesar 33,93\% dengan kriteria kualitatif cukup dengan presentase keidealan sebesar 50,88\%. Data ini menunjukkan bahwa produk draf RPP, LKS dan Modul Pembelajaran Siswa yang dikembangkan dengan model pembelajaran CIRC dapat diaplikasikan di SMP Negeri 1 Kota Bima.
\end{abstract}

Kata kunci: Draf RPP, LKS dan Modul Pembelajaran Siswa, Model Pembelajaran CIRC.

\begin{abstract}
This study aims to: (1) produce learning tools with the CIRC learning model in order to increase student understanding that is appropriate for use in the learning process, (2) learn the quality and student responses to learning devices that have been developed and used in the learning process. This research is a research development (Research and Development) with the Ploomp model. Field test subjects field 30 students of class VIII-7 in SMP Negeri 1 Bima City. The instrument used consisted of a validation sheet for the validator (3 mathematics teachers in SMP Negeri 1 Kota Bima), a student response questionnaire sheet, and an observation sheet containing an analysis questionnaire for students. Product quality data obtained from the validator is done by using descriptive analysis, which is processing the average score of quality aspects obtained from quantitative values into qualitative values using the ideal rating category criteria. Results of the assessment of products
\end{abstract}


consisting of lesson plans, worksheets and student learning models using data analysis consisting of quantitative and qualitative processing. The assessment is done by finding the average value of all aspects of the Protocol Assessment by the validator is 4.8 with very valid qualitative criteria. While 30 students have an average value of $33.93 \%$ with sufficient qualitative criteria with an ideal percentage of $50.88 \%$. This data shows that the draft RPP, LKS and Learning Module products developed with the CIRC learning model can be applied in SMP Negeri 1 Kota Bima.

Keywords: Draft RPP, Student Worksheet and Student Learning Module, CIRC Learning Model.

\section{PENDAHULUAN}

Program pendidikan matematika merupakan salah satu usaha dalam rangka memenuhi tujuan pendidikan nasional untuk mencerdaskan kehidupan bangsa dan membangun manusia Indonesia seutuhnya (Kusumah, 2018). Dalam pelaksanaan pembelajaran matematika memiliki sifat yang abstrak, sehingga pada proses penerapannya memerlukan pemahaman yang baik. Hal ini penting, karena dalam belajar matematika untuk memahami konsep yang baru, diperlukan prasyarat pemahaman konsep sebelumnya sehingga pengetahuan yang diperoleh oleh siswa itu dibangun atau dikonstruksi menurut pengalaman belajar masingmasing sesuai tahap perkembangan dan lingkungan sekitarnya. Menurut Suherman (1990) salah satu rendahnya penguasaan matematika siswa adalah guru tidak memberikan kesempatan yang cukup kepada siswa untuk membangun sendiri pengetahuannya. Matematika dipelajari oleh kebanyakan siswa secara langsung dalam bentuk yang sudah jadi (formal), karena matematika dipandang oleh kebanyakan guru sebagai suatu proses yang prosedural dan mekanistis.

Berdasarkan pengamatan awal yang dilakukan oleh peneliti di beberapa sekolah, kegiatan belajar mengajar masih terkesan guru sebagai pusat penyampai materi, dan hanya menggunakan buku ajar yang dipegang oleh guru sedangkan siswa hanya mendengarkan dan mencatat apa yang ditulis oleh gurunya, hal ini tentu bertolak belakang dengan kurikulum yang berlaku sekarang bahwa siswa dituntut lebih aktif dan kreatif dalam menemukan sendiri pemahamanya dengan bantuan gurunya. Peran guru sesuai dengan tuntutan kurikulum diharapkan sebagai fasilitator yang menjadi jembatan antara kebutuhan siswa dengan rancangan desain pembelajaran yang akan diberikan.

Proses pembelajaran matematika pada umumnya guru terlalu berkonsentrasi pada latihan menyelesaikan soal yang lebih bersifat prosedural mekanistis dari pada menanamkan pemahaman. Pada kegiatan pembelajaran guru biasanya menjelaskan konsep secara 
informative, memberikan contoh soal dan memberikan soal-soal latihan. Sehingga siswa dituntut untuk memahami materi tanpa memberikan dan menanamkan sebuah pemahaman yang seharusnya. Pemahaman siswa seharusnya ditanamkan melalui keaktifan siswa dalam pembelajaran. Hal ini menjadikan bahwa berhasil tidaknya suatu proses kegiatan pembelajaran bergantung pada kemampuan kreativitas guru menciptakan proses belajar yang sedemikian rupa sehingga dapat merangsang siswa untuk belajar secara aktif (Slameto dalam Sowanto, 2018). Dalam hal ini peneliti memberikan gambaran agar siswa dapat aktif dan meningkatkan pemahaman lewat model pembelajaran Cooperative tipe CIRC (Cooperative Integrated Reading and Competision). Pembelajaran kooperatif adalah model pembelajaran yang mengutamakan pembentukan kelompok sehingga siswa dituntut untuk aktif memahami dalam kelompok.

Pada bagian awal pembelajaran $C I R C$, siswa diharuskan untuk dapat menerima dengan senang anggota kelompok yang telah dipilihkan oleh guru. Guru kemudian memberikan penekanan terus menerus kepada siswa bahwa keberhasilan setiap individu bergantung pada keberhasilan kelompoknya. Selanjutnya, siswa mendiskusikan tugas yang diberikan oleh guru. Dalam hal ini guru bertindak sebagai fasilitator yang mengawasi kerja sama siswa dengan anggota kelompoknya dan bertanggung jawab menemukan informasi untuk memahami materi yang ada pada buku ajar. Tidak hanya bertanggung jawab menemukan informasi, siswa juga harus bertanggung jawab pada diri sendiri akan pemahaman menyelesaikan masalah-masalah yang ada. Selang beberapa menit, guru menunjuk salah seorang dalam kelompok untuk menjelaskan hasil diskusi di depan kelas. Penunjukkan secara acak oleh guru bertujuan untuk membuat siswa bertanggung jawab akan pemahaman per individu. Pembelajaran dengan model CIRC mengharuskan siswa untuk aktif dalam hal membaca, menulis dan seni berbahasa yang tentu akan menambah pemahaman siswa tersebut. Apabila siswa dapat menemukan, memberikan karya dengan membuat permisalan soal lain dan menjelaskan cara penyelesaiannya dapat dikatakan siswa telah mampu dan memahami apa yang dipelajari.

Seorang guru harus bisa menyiasati agar siswa mampu memahami apa yang diajarkan. Andang dkk (2019) mengungkapkan bahwa pengembangan perangkat pembelajaran diperlukan mengingat masih banyak guru mengajar dengan menggunakan metode lama, dimana guru bertindak sebagai penyampai informasi, guru menganggap diri tahu segalanya, sementara siswa hanya dapat mengetahui setelah mendapatkan informasi dari gurunya. 
Melalui perangkat pembelajaran yang dikembangkan (LKS, draf RPP serta Modul Pembelajaran Siswa), dalam penelitian ini muara akhir harapannya akan berdampak pada peningkatan pemahaman matematis siswa. Oleh karena itu, peneliti mencoba melakukan suatu penelitian dengan judul "Pengembangan Perangkat Pembelajaran CIRC (Cooperative Integrated Reading and Composition) dalam Meningkatkan Pemahaman Siswa pada Materi Pokok Perbandingan Siswa Kelas VIII SMP Negeri 1 Kota Bima”.

\section{METODE PENELITIAN}

Jenis penelitian ini adalah pengembangan (research development), dengan tahapan pengembangan model Plomp (Rochmad, 2012) yaitu: (1) Prelimenary Investigation (tahap investigasi awal), (2) Design (tahap perancangan), (3) Realization (tahap realisasi) dan (4) Test, Evaluation and Revision (tahap uji coba, evaluasi dan perbaikan). subjek penelitian ini adalah siswa SMPN 1 Kota Bima kelas VIII sebanyak 27 orang siswa.

\section{HASIL DAN PEMBAHASAN}

\section{Hasil Penelitian}

Penelitian ini merupakan penelitian pengembangan dengan tahapan pengembangan model Plomp, sehingga tahapan-tahapan dalam penelitian ini mulai dari Prelimenary Investigation (tahap investigasi awal), Design (tahap perancangan), Realization (tahap realisasi), dan tahap Test, Evaluation and Revision (tahap uji coba, evaluasi dan perbaikan) menjadi fokus penjabaran dalam hasil penelitian ini.

\section{Tahap Investigasi Awal (Prelimery Investigation)}

Tahap investigasi awal (prelimery investigation) di SMP Negeri 1 Kota Bima pada di kelas VIII-7 semester genap. Peneliti menginvestigasi terkait motivasi belajar, minat belajar, perhatian dan konsentrasi, apersepsi, kecerdasan serta kemampuan siswa.

\section{Tahap Perancangan (Design)}

Pada tahap ini peneliti menganalisis perangkat pembelajaran apa saja yang akan dikembangkan sesuai hasil investigasi awal di SMP Negeri 1 Kota Bima. Peneliti memutuskan untuk mengembangkan perangkat pembelajaran yang berupa draf RPP, LKS serta Modul Pembelajaran Siswa. 
Tahap Realisasi, Uji coba, Evaluasi dan Perbaikan (Realization, Test, Evaluation and Revision)

Perangkat Pembelajaran yang disebut prototipe pertama telah dinilai oleh validator ahli atau guru bidang studi matematika dengan beberapa aspek yaitu format materi pelajaran, kegiatan pembelajaran, penilaian pembelajaran, aspek kebahasaan serta kesinkronan prototipe yang dikembangkan menggunakan model pembelajaran $C I R C$, selanjutnya penilaian dari validator dihitung kemudian dideskripsikan. Adapun kriteria dari penilaian hasil validator adalah sebagai berikut :

Tabel 1. Jenjang Kriteria Penilaian Validitas Aspek dan Kriteria

\begin{tabular}{cc}
\hline Rentang Nilai Kuantitatif & Kualitas Kualitatif \\
\hline $4,5 \leq \mathrm{M} \leq 5$ & Sangat Valid \\
$3,5 \leq \mathrm{M} \leq 4,5$ & Valid \\
$2,5 \leq \mathrm{M} \leq 3,5$ & Cukup valid (revisi kecil) \\
$1,5 \leq \mathrm{M} \leq 2,5$ & Kurang valid (revisi besar) \\
$\mathrm{M} \leq 1,5$ & Tidak Valid (revisi total) \\
\hline
\end{tabular}

Hasil penilaian prototipe pertama dengan rata-rata 2,9 kategori cukup valid, peneliti melakukan revisi kembali dengan mengikuti kritik dan saran dari validator sehingga perangkat pembelajaran layak digunakan. Prototipe kedua menambahkan langkah-langkah agar sesuai dengan model pembelajaran CIRC tidak mengubah LKS dan merubah alokasi pertemuan dalam draf RPP menjadi 2x pertemuan, kemudian meminta kesediaan validator untuk menilai kembali prototipe yang telah direvisi. Hasil penilaian prototipe kedua oleh validator adalah 3,4 berarti prototipe kedua pun cukup valid namun masih membutuhkan revisi. Peneliti kembali melakukan revisi berdasarkan kritik dan saran dari validator.

\section{Tahap Penerapan (Implementation)}

Setelah prototipe divalidasi oleh validator sebanyak 3 kali dan diujikan selama 3 kali pula pada siswa, akhirnya peneliti mendapatkan kualitas prototipe dengan kriteria sangat valid. Peneliti juga memberikan angket respon siswa dengan rata-rata sebesar 33,93\% dengan kriteria kualitatif "cukup" dengan presentase keidealan sebesar 50,88 \%. 


\section{Hasil Analisis}

Pada hasil analisis penilaian validator terhadap draf RPP, LKS dan Modul Pembelajaran, disajikan dalam tabel 2 berikut:

Tabel 2. Hasil Validasi Prototipe Pertama dari 3 Validator

\begin{tabular}{cccc}
\hline No. & Aspek & Rata-rata & Keterangan \\
\hline 1. & Format Materi & 2,5 & Kurang Valid \\
Kegiatan & 2,3 & Kurang Valid \\
Pembelajaran & Penilaian & 2,7 & Cukup Valid \\
3. & $\begin{array}{c}\text { Pembelajaran } \\
\text { Aspek }\end{array}$ & 3,8 & Valid \\
4. & $\begin{array}{c}\text { Kebahasaan } \\
\text { Kesinkronan } \\
\text { P. }\end{array}$ & 2,2 & Kurang Valid \\
& Prototipe & 2,7 & Cukup Valid \\
\hline
\end{tabular}

Hasil penilaian kepraktisan perangkat pembelajaran yang dikembangkan meliputi draf RPP, LKS dan modul pembelajaran siswa, berdasarkan penilaian validator disajikan dalam tabel berikut :

Tabel 3. Hasil Penilaian Kepraktisan Perangkat Pembelajaran

\begin{tabular}{cccc}
\hline $\begin{array}{c}\text { Perangkat } \\
\text { Pembelajaran }\end{array}$ & Validator & Nilai & Keterangan \\
\hline $\begin{array}{c}\text { Draf RPP } \\
\text { LKS } \\
\text { dan }\end{array}$ & 1 & $\mathrm{C}$ & \\
$\begin{array}{c}\text { Modul } \\
\text { Pembelajaran Siswa }\end{array}$ & 2 & $\mathrm{C}$ & $\begin{array}{c}\text { Dapat Digunakan dengan } \\
\text { Revisi Besar }\end{array}$ \\
\hline
\end{tabular}

Berdasarkan tabel 3, bahwa Perangkat Pembelajaran yang dikembangkan dapat digunakan dengan banyak revisi dan masih belum dapat dikatakan praktis. Prototipe harus direvisi kembali, kemudian prototipe kedua hasil revisi kembali divalidasi oleh validator.

Tabel 4. Jenjang Kriteria Penilaian Ideal Prototipe

\begin{tabular}{cc}
\hline Nilai & Kualitas Kualitatif \\
\hline $\mathrm{M}>52,5$ & Sangat Baik \\
$37,5<\mathrm{M}<52,5$ & Baik \\
\hline
\end{tabular}




$\begin{array}{cc}22,5<\mathrm{M}<37,5 & \text { Cukup Baik } \\ 7,5 \leq \mathrm{M}<22,5 & \text { Kurang Baik } \\ \mathrm{M} \leq 7,5 & \text { Tidak Baik }\end{array}$

Dari tabel 4 prototipe pertama cukup baik dengan persentase keidealan 40,87\%. Prototipe kemudian direvisi dan menghasilkan prototipe kedua. Penilaian kembali dilakukan oleh validator terhadap prototipe kedua dengan aspek yang sama. Hasil penilaian secara singkat disajikan dalam tabel 5 berikut:

Tabel 5. Hasil Validasi Prototipe Kedua dari 3 Validator

\begin{tabular}{cccc}
\hline No. & Aspek & Rata-rata & Keterangan \\
\hline 1. & Format Materi & 3 & Cukup Valid \\
2. & $\begin{array}{c}\text { Kegiatan } \\
\text { Pembelajaran } \\
\text { Penilaian }\end{array}$ & 3,2 & Cukup Valid \\
3. & 3,5 & Cukup Valid \\
4. & $\begin{array}{c}\text { Aspek } \\
\text { Kebahasaan } \\
\text { Kesinkronan } \\
\text { Prototipe }\end{array}$ & 3,5 & Cukup Valid \\
& Rata-rata & 3,2 & Cukup Valid \\
\hline
\end{tabular}

Hasil penilaian kepraktisan perangkat pembelajaran berdasarkan penilaian validator disajikan dalam tabel berikut:

Tabel 6. Hasil Penilaian Kepraktisan Perangkat Pembelajaran

\begin{tabular}{|c|c|c|c|}
\hline $\begin{array}{c}\text { Perangkat } \\
\text { Pembelajaran } \\
\end{array}$ & Validator & Nilai & Keterangan \\
\hline Draf RPP, & 1 & B & $\begin{array}{l}\text { Dapat digunakan dengan } \\
\text { revisi kecil }\end{array}$ \\
\hline $\begin{array}{c}\text { LKS } \\
\text { dan } \\
\text { Modul }\end{array}$ & 2 & B & $\begin{array}{c}\text { Dapat digunakan dengan } \\
\text { revisi kecil }\end{array}$ \\
\hline $\begin{array}{l}\text { Modul } \\
\text { Pembelajaran Siswa }\end{array}$ & 3 & $\mathrm{C}$ & $\begin{array}{l}\text { Dapat digunakan dengan } \\
\text { revisi besar }\end{array}$ \\
\hline
\end{tabular}

Berdasarkan table 6, Perangkat Pembelajaran yang dikembangkan dapat digunakan dengan banyak revisi dan belum dapat dikatakan praktis, karena validator ketiga masih menilai prototipe dengan nilai $\mathrm{C}$ atau direvisi kembali dan divalidasi oleh validator. Prototipe 
kedua yang dihasilkan tetap diuji cobakan dengan hasil skor 896 dan nilai rata-rata adalah $32 \%$. Hasil penilaian kepraktisan perangkat pembelajaran dapat dilihat pada tabel dibawah ini:

Tabel 7. Jenjang Kriteria Penilaian Ideal Prototipe

\begin{tabular}{cc}
\hline Nilai & Kualitas Kualitatif \\
\hline $\mathrm{M}>52,5$ & Sangat Baik \\
$37,5<\mathrm{M}<52,5$ & Baik \\
$22,5<\mathrm{M}<37,5$ & Cukup Baik \\
$7,5 \leq \mathrm{M}<22,5$ & Kurang Baik \\
$\mathrm{M} \leq 7,5$ & Tidak Baik \\
\hline
\end{tabular}

Dari tabel 7, kualitas pembelajaran dengan prototype pertama cukup baik dengan persentase keidealan $49,78 \%$. Selanjutnya prototipe kedua dan Prototipe ketiga dapat dilakukan revisi kembali oleh validator. Hasil penilaian secara singkat disajikan dalam tabel berikut :

Tabel 8. Hasil Validasi Prototipe ketiga oleh 3 validator

\begin{tabular}{cccc}
\hline No. & Aspek & Rata-rata & Keterangan \\
\hline 1. & Format Materi & 4,8 & Sangat Valid \\
2. & $\begin{array}{c}\text { Kegiatan } \\
\text { Pembelajaran } \\
\text { Penilaian }\end{array}$ & 4,8 & Sangat Valid \\
3. & 4,7 & Sangat Valid \\
Pembelajaran & Aspek & 4,8 & Sangat Valid \\
5. & $\begin{array}{c}\text { Kebahasaan } \\
\text { Kesinkronan } \\
\text { Prototipe }\end{array}$ & 4,8 & Sangat Valid \\
& Rata-rata & 4,8 & Sangat Valid \\
\hline
\end{tabular}

Selanjutnya draf RPP, LKS dan Modul Pembelajaran Siswa berdasarkan penilaian validator disajikan dalam tabel berikut :

Tabel 9. Hasil Penilaian Kepraktisan Perangkat Pembelajaran

\begin{tabular}{cccc}
\hline Perangkat & Validator & Nilai & Keterangan \\
Pembelajaran & & & \\
\hline Draf RPP & 1 & A & Dapat digunakan \\
LKS & & & setelah \\
dan & & & $\begin{array}{c}\text { beberapa kali revisi } \\
\text { Dapat digunakan } \\
\text { Modul }\end{array}$ \\
Pembelajaran & 2 & A & setelah \\
\hline
\end{tabular}




\begin{tabular}{ccc}
\hline Siswa & & $\begin{array}{c}\text { beberapa kali revisi } \\
\text { Dapat digunakan } \\
\text { setelah }\end{array}$ \\
& A & \begin{tabular}{c} 
beberapa kali revisi \\
\hline
\end{tabular} \\
\hline
\end{tabular}

Berdasarkan tabel 9, Perangkat Pembelajaran yang dikembangkan dapat digunakan karena validator ketiga menilai prototipe dengan nilai A. Prototipe ketiga yang dihasilkan diuji cobakan kembali dan memberikan angket yang sama berisi pernyataan dengan 4 aspek yang sama pula, dengan hasil skor 916 dan nilai rata-rata adalah 33,93\% .

Tabel 10. Jenjang Kriteria Penilaian Ideal Prototipe

\begin{tabular}{cc}
\hline Nilai & Kualitas Kualitatif \\
\hline $\mathrm{M}>52,5$ & Sangat Baik \\
$37,5<\mathrm{M}<52,5$ & Baik \\
$22,5<\mathrm{M}<37,5$ & Cukup Baik \\
$7,5 \leq \mathrm{M}<22,5$ & Kurang Baik \\
$\mathrm{M} \leq 7,5$ & Tidak Baik \\
\hline
\end{tabular}

Dari tabel diatas kualitas pembelajaran prototipe ketiga cukup baik dengan persentase keidealan $50,88 \%$.

\section{Pembahasan}

Perangkat pembelajaran matematika dengan model pembelajaran CIRC yang dikembangkan yang telah dinilai valid oleh para ahli (validator), sehingga perangkat pembelajaran dikatakan valid. Lembar validasi berisi 12 kriteria penilaian akan draf RPP, LKS serta modul pembelajaran siswa yang telah dikembangkan dan harus dinilai oleh validator. Kriteria tersebut dibagi menjadi 5 aspek.

Aspek penilaian pengembangan pembelajaran dapat disimpulkan bahwa pembahasan materi sesuai dengan kompetensi dasar, unsur-unsur pembelajaran CIRC termuat dalam produk yang dihasilkan, bahasa yang digunakan tepat dan produk pembelajaran dapat menarik minat siswa. Jumlah penilaian dari validator pada aspek ini adalah 72 dengan skor rata-rata 4,8. Sedangkan aspek penilaian kegiatan pembelajaran terdapat 6 kriteria penilaian, pada modul pembelajaran siswa terdapat kolom menalar, kesesuaian cara meneliti fakta, materi yang ada saling berhubungan, kegiatan pembelajaran mampu membuat siswa bereksplorasi. Pada draf RPP, pengalokasian waktu serta terdapat langkah-langkah pembelajaran dengan 
komponen pembelajaran model CIRC. Jumlah penilaian adalah 86 dengan skor rata-rata adalah 4,8 .

Penilaian aspek pengembangan ini adalah 28 dengan skor rata-rata 4,7, sedangkan aspek kebahasaan terdapat dua kriteria penilaian, penggunaan kata, bahasa dan kalimat yang sederhana dalam produk pembelajaran sehingga siswa mudah memahami materi. Jumlah penilaian aspek ini adalah 29 dengan skor rata-rata 4,8. Selain penilaian validasi terhadap produk yang dikembangkan oleh validator, dilakukan pula penilaian oleh siswa terhadap kegiatan pembelajaran dengan Modul pembelajaran siswa dan lembar kerja siswa (LKS). Terdapat 12 pernyataan acak yang mengandung 4 aspek, yakni aspek motivasi siswa, aspek penyerapan materi, aspek kenyamanan siswa serta aspek pendalaman gaya belajar siswa. Pernyataan nomor 1 dan 11 termasuk ke dalam aspek motivasi siswa, pernyataan nomor 2 dan 4 aspek penyerapan materi, pernyataan 3, 5, 6 dan 12 Aspek Kenyamanan Siswa, pernyataan nomor 7, 8, 9 dan 10 merupakan aspek pendalaman gaya belajar siswa.

Adapun perbandingan penilaian menurut siswa berdasarkan perhitungan per Aspek selama tiga kali pengujian adalah sebagai berikut :

Tabel 11. Perbandingan Penilain Peraspek

\begin{tabular}{cccccc}
\hline & \multicolumn{5}{c}{ Aspek Penilaian } \\
\cline { 2 - 6 } Prototipe & A & B & C & D & Jumlah \\
\hline 1 & 142 & 123 & 254 & 215 & 734 \\
2 & 184 & 146 & 329 & 237 & 896 \\
3 & 203 & 143 & 346 & 224 & 916 \\
\hline
\end{tabular}

Perbandiangan pemahaman siswa dapat dilihat dari sejauh mana siswa memahami pelajaran yaitu membandingkan skor pernyataan nomor 2 dan 4 pada aspek B (Pendalaman materi). Pernyataan nomor 2 berisi pernyataan bahwa siswa bisa memahami pelajaran matematika, sedangkan pernyataan nomor empat menyatakan bahwa siswa mengalami kesulitan dalam memahami materi dengan produk yang dikembangkan. Adapun perbandingannya sebagai berikut:

Tabel 11. Perbandingan Pemahaman Siswa Berdasarkan Tingkat Kesukaran Soal

\begin{tabular}{crcc}
\hline Pernyataan & \multicolumn{3}{c}{ Uji Coba ke -(Skor) } \\
\cline { 2 - 4 } (Nomor) & 1 & 2 & 3 \\
\hline Mudah (2) & 72 & 94 & 103 \\
Sulit / Sukar (4) & 51 & 52 & 41 \\
\hline
\end{tabular}


Jika dilihat dari tabel 11, persentase siswa mudah memahami pelajaran matematika pada pertemuan pertama sebesar $60 \%$, pertemuan kedua $78,3 \%$ dan pada pertemuan ketiga 85,5\%. Sedangkan persentase siswa sukar atau sulit memahami pelajaran matematika pada pertemuan pertama sebesar $42,5 \%$, pertemuan kedua $43,3 \%$ dan pertemuan ketiga sebesar $34 \%$. Hal ini menunjukkan bahwa adanya peningkatan porsentase dalam kemudahan siswa memahami pelajaran. Persentase dalam tingkat kesukaran memahami pelajaran matematika semakin menurun, dapat dilihat pula pada tabel 4.9 :

Tabel 12. Perbandingan Hasil Penilaian

\begin{tabular}{cc}
\hline Prototipe & Kualitas Pembelajaran \\
\hline 1 & $40,87 \%$ \\
2 & $49 \%$ \\
3 & $50,88 \%$ \\
\hline
\end{tabular}

Penilaian kualitas pembelajaran dengan prototipe pertama hingga prototipe ketiga mengalami peningkatan. Dalam hal ini perangkat pembelajaran yang dikembangkan dapat meningkatkan pemahaman siswa.

\section{KESIMPULAN}

Kesimpulan yang dapat diambil adalah sebagai berikut: (1) Produk Perangkat Pembelajaran yang telah dikembangkan (Modul Pembelajaran Siswa, draf LKS serta draf RPP) dengan menggunakan model pembelajaran CIRC di dalamnya dapat meningkatkan pemahaman siswa dan layak digunakan dalam proses pembelajaran khususnya di SMP Negeri 1 Kota Bima; (2) Kualitas produk akhir setelah adanya beberapa revisi dari 3 validator mendapatkan skor rata-rata semua aspek sebesar 4,8 dengan kriteria kualitatif sangat valid. Sedangkan persentase penilaian dari 30 siswa yang berjumlah 916 memiliki rata-rata nilai sebesar 33,93\% dengan persentase keidealan rata-rata sebesar 50,88\%.

\section{REKOMENDASI}

Adapun rekomendasi pengembangan produk lebih lanjut adalah Draf RPP, LKS serta modul pembelajaran siswa dengan model pembelajaran CIRC dapat dikembangkan lebih lanjut antara lain: (1) Mengembangkan perangkat pembelajaran ini untuk jenjang kelas yang berbeda (SD/MI atau SMA/MA); (2) Mengaplikasikan produk di berbagai mata pelajaran, 
karena sebelumnya matematika dianggap sebagai pelajaran yang tidak bisa diterapkan model pembelajaran $C I R C$ di dalamnya.

\section{UCAPAN TERIMAKASIH}

Ucapan terima kasih penulis kepada kepala sekolah serta Guru-guru khususnya guru matematika SMPN 1 Kota Bima yang memberikan ijin kepada peneliti untuk melakukan penelitian

\section{REFERENSI}

Andang, A., Sowanto, S., \& Saifullah, S. (2019). PENGEMBANGAN LEMBAR KERJA SISWA PEMBELAJARAN MATEMATIKA DENGAN PENDEKATAN KONSTRUKTIVISTIK MATERI POKOK TEOREMA PYTHAGORAS. SUPERMAT (JURNAL PENDIDIKAN MATEMATIKA), 3(2), 46-64.

Kusumah, Y. S. (2018, May). Enhancing students' mathematical representation and selfefficacy through situation-based learning assisted by geometer's sketchpad program. In Journal of Physics: Conference Series (Vol. 1013, No. 1, p. 012107). IOP Publishing.

Rochmad, R. (2012). Desain model pengembangan perangkat pembelajaran matematika. Kreano, Jurnal Matematika Kreatif-Inovatif, 3(1), 59-72.

Suherman, E., \& Sukjaya, Y. (1990). Petunjuk praktis untuk melaksanakan evaluasi pendidikan matematika. Bandung: Wijayakusumah, 157.

Sowanto, S. (2018). BAHAN AJAR PADA MATERI GARIS SINGGUNG LINGKARAN DENGAN PENDEKATAN SAINTIFIK UNTUK SISWA SMP. Kalamatika: Jurnal Pendidikan Matematika, 3(1), 63-80. 